\title{
STUDY OF CERVICAL CANCER AND ITS PREVALENCE IN RURAL AREAS OF THANJAVUR DISTRICT, TAMILNADU
}

\author{
Al Santhi' ${ }^{1}$, Muturamu Poovathi², Krishnan Govindaraman Padmanaban ${ }^{3}$, Rajapandian Shobana ${ }^{4}$ \\ 1 Professor and HOD, Department of Pathology, Thanjavur Medical College, Tamilnadu. \\ 2Professor, Department of Obstetrics and Gynaecology, Thanjavur Medical College, Tamilnadu. \\ ${ }^{3}$ Associate Professor, Department of Pathology, Thanjavur Medical College, Tamilnadu. \\ ${ }^{4}$ Assistant Professor, Department of Pathology, Thanjavur Medical College, Tamilnadu.
}

\begin{abstract}
BACKGROUND

Cervical cancer is one of the India's major health problem and a major cause of death in women.

OBJECTIVES

To find out the prevalence of cervical cancer in rural areas by effective screening methods.

\section{SETTING}

Study was conducted in Thanjavur Medical College Hospital, Thanjavur.

\section{MATERIALS AND METHODS}

Study was carried from January 2013 to December 2014. A total of 6420 women were screened under Pilot Screening Programme Project in Thanjavur District. VIA [Visual inspection of cervix after application of acetic acid] and VILI [Visual inspection after application of Lugol's Iodine] was done. Colposcopic guided biopsy was taken and histopathological examination was done. Its relation to HPV infection was proved with immuno-histochemical markers Ki 67 and P16INK4.
\end{abstract}

\section{RESULTS}

Of the 6420 women screened for cancer cervix, 7.9\% were found to have cervical intraepithelial neoplasia I [CIN I], 3.2\% with CIN II, $1.7 \%$ with CIN III. A total of $9.4 \%$ women had frank carcinoma of cervix, out of which $9.1 \%$ was squamous cell carcinoma, $.2 \%$ was adenocarcinoma and other tumours constituted about .1\%.

\section{KEYWORDS}

Cervical Cancer, Human Papilloma Virus, Cervical Intraepithelial Neoplasia, Colposcopy.

HOW TO CITE THIS ARTICLE: Santhi AL, Poovathi M, Padmanaban KG, et al. Study of cervical cancer and its prevalence in rural areas of Thanjavur District, Tamilnadu. J. Evolution Med. Dent. Sci. 2016;5(9):373-375, DOI: 10.14260/jemds/2016/85

\section{INTRODUCTION}

The cancer that can be easily prevented by effective screening methods and early diagnosis is cancer cervix. Globally, cancer cervix is the second most common cancer next to cancer breast. But in India, it is the most common cancer. WHO study says about 1.3 lakh women in India are diagnosed as cancer cervix every year and approximately 74,000 die every year. Around $27 \%$ cancer cervix deaths in the world occur in India. This is about $1 / 3$ of global cancer cervix deaths. Age standardized death rate is $9.5 / 1,00,000$.

The morbidity and mortality of cancer cervix is on decline due to early diagnosis and better treatment modalities, which is made possible only by effective screening methods. Much credit of this screening belongs to the Papanicolaou cytological test in detecting precancerous lesions. [Cervical Intraepithelial Neoplasia] and easy accessibility of the cervix to colposcopy and biopsy. ${ }^{1}$

The risk of progression of CIN I, CIN II and CIN III to frank cervical cancer is $1 \%, 5 \%$ and $12 \%$ respectively. ${ }^{2}$

Financial or Other, Competing Interest: None.

Submission 17-12-2015, Peer Review 06-01-2016,

Acceptance 19-01-2016, Published 29-01-2016.

Corresponding Author:

Dr. Al Santhi,

10, Philomina Nagar,

Thanjavur.

E-mail: santhiminu@gmail.com

DOI: $10.14260 /$ jemds/2016/85
Thus, it is evident that screening methods have increased the detection of potentially curable cancers and the detection and eradication of pre-invasive lesions, some of which would progress to cancer if not discovered. ${ }^{3}$

Pilot Screening Programme [PSP] was started in Thanjavur and Theni districts by the Government of Tamilnadu for cervical cancer screening. Patients who were positive for cervical intraepithelial neoplasia and frank cervical cancer were referred to Tertiary Institution for further treatment modalities.

\section{MATERIALS AND METHODS}

The present cross-sectional study was carried out at the Department of Pathology, Thanjavur Medical College, Tamilnadu, from January 2013 to December 2014. Total of 6420 women were screened during this study by VIA [Visual inspection of cervix after application of Acetic acid] and VILI [Visual inspection of cervix after application of Lugol's Iodine] Colposcopic guided biopsy was taken from the VIA, VILI positive areas and subjected for histopathological examination. Then the positive cases [Either pre-invasive or invasive] were subjected to immunohistochemistry with p16INK4 and Ki 67 to correlate the HPV [Human Papilloma virus] infection.

HPV DNA Is detected by hybridization techniques in over 95\% of cervical cancer. ${ }^{4}$ HPV also causes other squamous tumours or proliferative lesions of skin and mucous 
membrane. ${ }^{5}$ Of late, vaccines are directed against Human Papilloma viruses can prevent the infection and the development of the precancerous disorders. 6,7

\section{RESULTS}

In the present study, 6420 women were screened. Incidence of the various precancerous [CIN I, CIN II, III] and invasive lesions are shown in Table 1.

\begin{tabular}{|c|c|c|c|}
\hline & Year 2013 & Year 2014 & Total \\
\hline Total cervix biopsy & 3198 & 3222 & 6420 \\
\hline CIN I & 210 & 298 & 508 \\
\hline CIN II & 28 & 180 & 208 \\
\hline CIN III & 13 & 99 & 112 \\
\hline SQUAMOUS CELL CA & 318 & 271 & 589 \\
\hline ADENOCARCINOMA & 9 & 7 & 16 \\
\hline OTHER TUMOURS & 5 & 3 & 8 \\
\hline
\end{tabular}

Five hundred and eight women were found to have CIN I 208 women with CIN II and 112 patients with CIN III. A fairly large number of patients, i.e. 613 were affected with frank carcinoma, out of which 589 patients [96\%] were found to have squamous cell carcinoma, 16 patients [2.6\%] with adenocarcinoma and 8 patients [1.30\%] with other tumours.

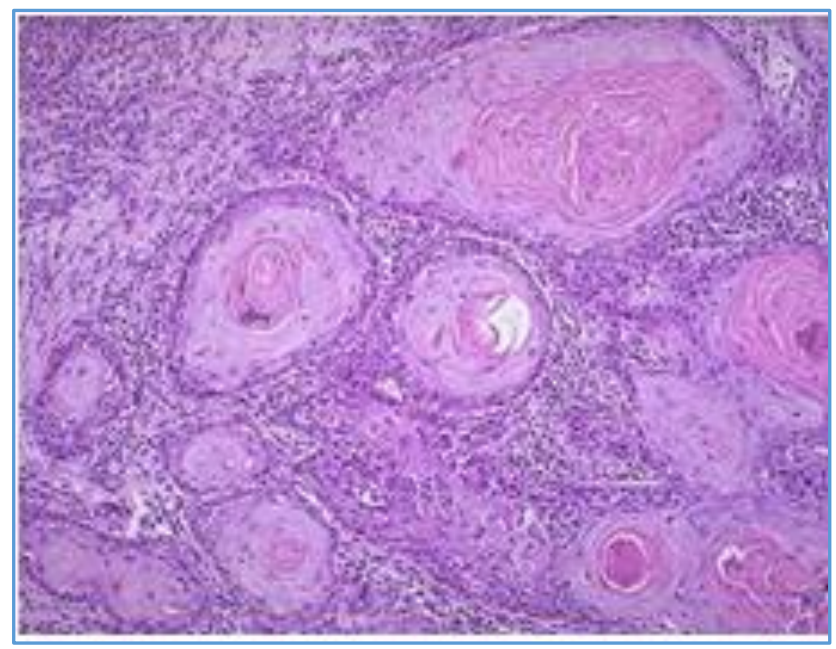

Fig. 1: Squamous cell carcinoma of cervix

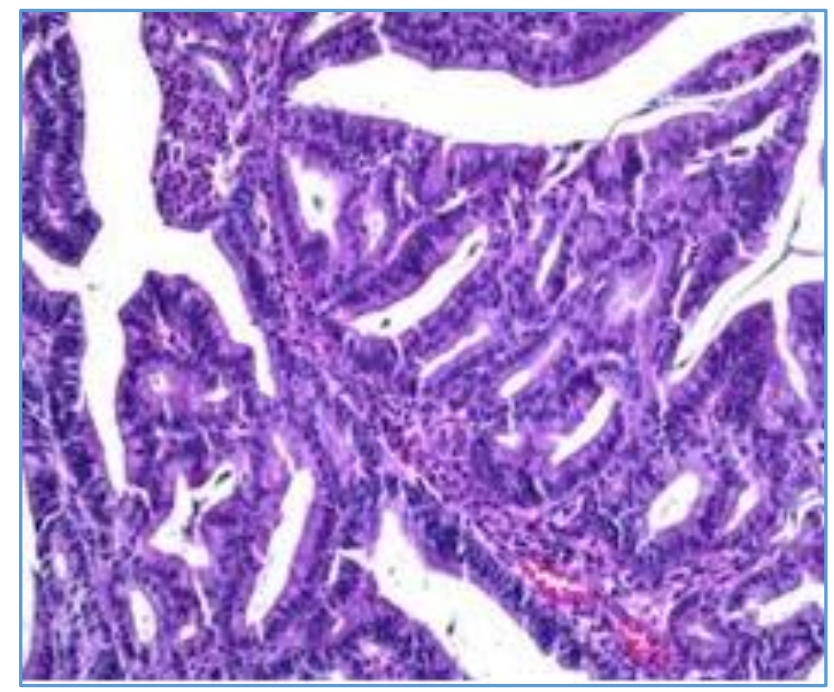

Fig. 2: Adenocarcinoma of cervix
Distribution of grades of CIN in various study groups.

\begin{tabular}{|c|c|c|c|}
\hline STUDIES [AUTHORS] & CIN I & CIN II & CIN III \\
\hline MURPHY et al. & $32.4 \%$ & $28.2 \%$ & $39.3 \%$ \\
\hline KATCHEVA et al. & $15.7 \%$ & $42.1 \%$ & $42.1 \%$ \\
\hline ZHANG et al. & $54 \%$ & $24 \%$ & $22 \%$ \\
\hline K GUPTA et al. & $58 \%$ & $25 \%$ & $17 \%$ \\
\hline PRESENT STUDY & $7.9 \%$ & $3.2 \%$ & $1.7 \%$ \\
\hline
\end{tabular}

In our study the percentage of distribution of grades of CIN is low because of effective screening methods, improved personal hygiene and low parity.

\section{DISCUSSION}

Cancer of cervix evolves slowly over many years. During this interval the only sign of disease may be the shedding of abnormal cells from the cervix. Therefore Pap's smear should be performed on all women after they become sexually active. Once a cytological abnormality is detected, patients require further colposcopic examination and biopsy. CIN [cervical intraepithelial neoplasia] lesions are characterized on colposcopic examination by white patches on the cervix after application of acetic acid. 8

In addition, distinct vascular mosaic or punctuation patterns can be observed. Highly abnormal vascular patterns accompany invasive cervical cancer. If abnormalities are visualised, they are confirmed by histopathological examination of punch biopsy taken from representative areas and also by immune-histochemical identification of increased expression of host cell biomarkers such as p16INK4, Cyclin E and Ki-67.9

P-16 is a cyclin kinase inhibitor. Cells infected with Human Papilloma Virus show overexpression of P-16. Intense brown staining indicates high risk oncogenic HPV virus. Ki-67 is a marker of cellular proliferation. In normal squamous cells it is confined to basal layers. But in dysplasia, seen throughout the entire thickness indicating abnormal expansion of epithelial proliferation zone. Both P-16 and Ki-67 staining correlates with HPV infection and useful in confirmation of diagnosis. They are the promising markers of cervical neoplasm screening. In this study, 50 cases were subjected for immune-histochemical markers, sensitivity was

HPV testing also aids in identifying the infected individuals. The classification of premalignant squamous cervical lesions as CIN I, II, III is now revised as low-grade squamous intraepithelial lesion [LSIL] and high-grade squamous intraepithelial region [HSIL]. ${ }^{10}$

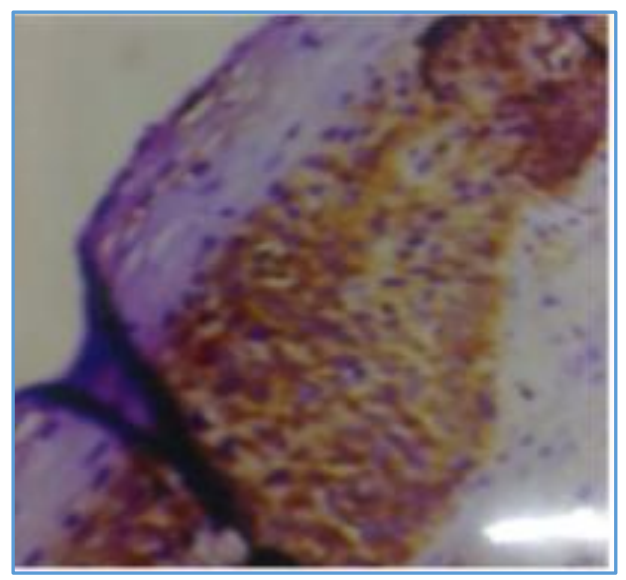

Fig. 3: p 16 INK4 expression in CIN II 


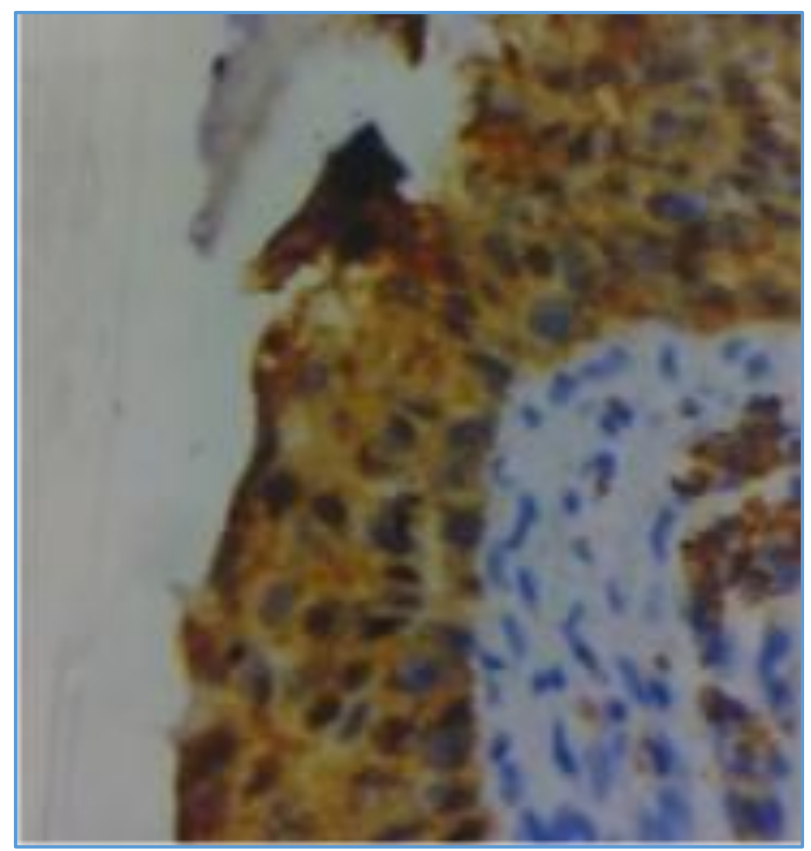

Fig. 4: $p 16$ INK4 expression in CA in situ

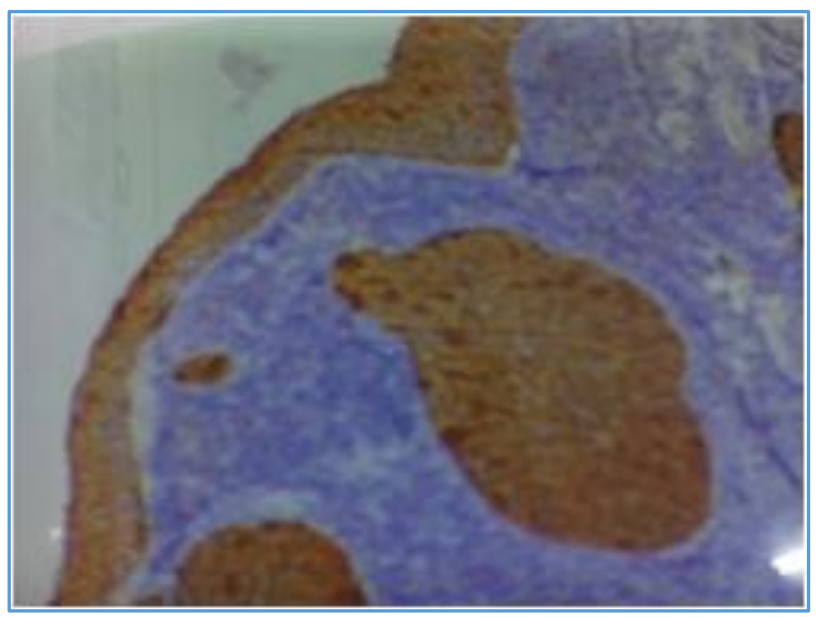

Fig. 5: p I6 INK4 expression in microinvasive CA

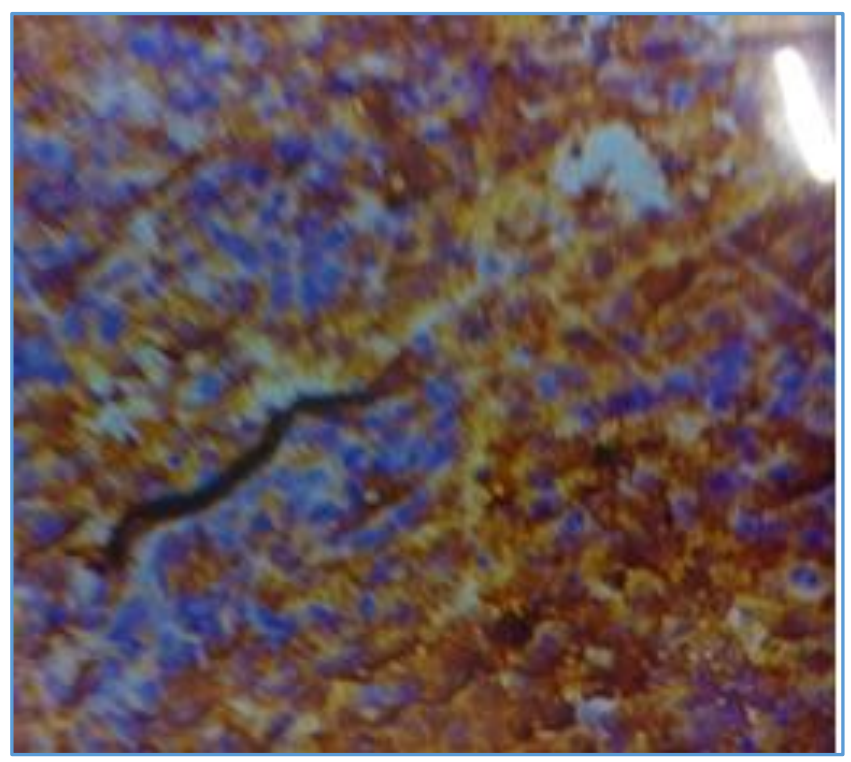

\section{CLASSIFICATION OF PREMALIGNANT SQUAMOUS} CERVICAL LESIONS

\begin{tabular}{|c|c|c|}
\hline Mild dysplasia & CIN I & LSIL \\
\hline Moderate dysplasia & CIN II & HSIL \\
\hline Severe dysplasia & CIN III & HSIL \\
\hline Carcinoma in situ & CARCINOMA IN SITU & HSIL \\
\hline
\end{tabular}

Most LSIL lesions regress spontaneously. Only $10 \%$ progress to HISL. Progression to invasive cancers take few months to 10 years. More than $80 \%$ of LSIL and $100 \%$ of HSIL are associated with HPV 16 and 18.

\section{CONCLUSION}

Thus early detection of cancer cervix by prompt screening helps in identification of precancerous lesions of cervix at the earliest and help in early treatment to have a good prognosis. This study is relatively a huge study in which 6420 women are screened and $12.8 \%$ of women are identified in precancerous state and $9.4 \%$ of women had frank invasive cancer.

\section{REFERENCES}

1. Crum CP, et al. Pathology of early cervical neoplasia, 1996, New York, Churchill Livingstone, 9;119.

2. Wright TC, Jr; Cox JT; Massad LS; et al. 2001. Consensus guidelines for the management of women with cervical cytological abnormalities. JAMA 2002;287:2120-2129.

3. Robbins and Cotran- Pathologic Basis of Disease. 7th edition, chapter 22, page 1075.

4. Zur Hausen H. Papillomavirus infection. A major cause of human cancers. Biochim Biophys Acta. 1996 Oct 9;1288(2):F55-78.

5. Koutsky L. Epidemiology of genital human Papillomavirus infection. Am J Med 1997;102:3

6. Zhou J, Sun XY, Stenzel DJ, et al. Expression of vaccinia recombinant HPV $16 \mathrm{~L} 1$ and L2 ORF proteins in epithelial cells is sufficient for assembly of HPV virion-like particles, Virology, 1991;185;251

7. Koutsky LA, Ault KA, Wheeler CM, et al. A controlled trial of human Papillomavirus type 16 vaccine, $N$ Eng J Med 2002;347;1645-51.

8. Flowers LC, McCall MA. Diagnosis and management of cervical intraepithelial neoplasia. Obstet Gynaecol Clin North Am 2001;28:667-84.

9. Keating JT, Crum CP. Surrogate biomarkers of HPV infection of cervical neoplasia, screening and diagnosis. Adv Anat Pathology 2001;8:83-92.

10. Ostor AG. Natural history of cervical intraepithelial neoplasia; a critical review. Int J Gynaecol Pathology 1993;12:186-92.

Fig. 6: Expression of p I6 INK4 in squamous cell CA 